\title{
MEDIIK: Design and Manufacturing of an Emergency Ventilator Against COVID-19 Pandemic
}

\author{
Javier Vazquez-Armendariz \\ Escuela de Ingenieria y Ciencias, \\ Tecnologico de Monterrey, Monterrey, \\ Mexico \\ a00824090@itesm.mx \\ Jan Lammel-Lindemann \\ Escuela de Ingenieria y Ciencias, \\ Tecnologico de Monterrey, Monterrey, \\ Mexico \\ janlammel@tec.mx \\ Hiram Uribe-Hernandez \\ 3D Factory MX, Monterrey, Mexico \\ hiram@3dfactory.mx
}

Marcos D. Moya-Bencomo

Escuela de Ingenieria y Ciencias,

Tecnologico de Monterrey, Monterrey,

Mexico

marcosmoya@tec.mx

Nicolas J. Hendrichs-Troeglen

Escuela de Ingenieria y Ciencias,

Tecnologico de Monterrey, Monterrey, Mexico

nicolas.hendrichs@tec.mx

Cesar Caamal-Torres

Escuela de Medicina y Ciencias de la

Salud, Tecnologico de Monterrey,

Monterrey, Mexico

dr.camaal@gmail.com

Adriana Vargas-Martinez

Escuela de Ingenieria y Ciencias,

Tecnologico de Monterrey, Monterrey,

Mexico

adriana.vargas.mtz@tec.mx

\author{
Victor Segura Ibarra \\ Escuela de Medicina y Ciencias de la \\ Salud, Tecnologico de Monterrey, \\ Monterrey, Mexico \\ victor.segura@tec.mx
}

J. Israel Martinez-Lopez

Escuela de Ingenieria y Ciencias,

Tecnologico de Monterrey, Monterrey, Mexico

israel.mtz@tec.mx

Ricardo Liñan-Garcia

3D Factory MX, Monterrey, Mexico ricardo@3dfactory.mx

Agustin Carvajal-Rivera

Escuela de Ingenieria y Ciencias,

Tecnologico de Monterrey, Monterrey, Mexico

agustin.carbajal@tec.mx

Miguel Mendoza-Machain

Automated Data Systems, Monterrey, Mexico

ads@adsmex.com

Julio Noriega-Velasco

Escuela de Ingenieria y Ciencias,

Tecnologico de Monterrey, Monterrey,

Mexico

jnoriega@tec.mx

Eduardo Gonzalez-Mendivil ${ }^{*}$

Escuela de Ingenieria y Ciencias,

Tecnologico de Monterrey, Monterrey,

Mexico

egm@tec.mx

Ciro A. Rodriguez

Escuela de Ingenieria y Ciencias,

Tecnologico de Monterrey, Monterrey,

Mexico

ciro.rodriguez@tec.mx

\author{
Luis H. Olivas-Alanis \\ Escuela de Ingenieria y Ciencias, \\ Tecnologico de Monterrey, Monterrey, \\ Mexico \\ a01230117@itesm.mx \\ Erick Ramirez-Cedillo \\ Escuela de Ingenieria y Ciencias, \\ Tecnologico de Monterrey, Monterrey, \\ Mexico \\ erickramce@tec.mx \\ Rogelio Letechipia-Duran \\ 3D Factory MX, Monterrey, Mexico \\ rogelio@3dfactory.mx \\ Azael Cortes-Capetillo \\ Escuela de Ingenieria y Ciencias, \\ Tecnologico de Monterrey, Monterrey, \\ Mexico \\ azael.capetillo@tec.mx \\ Arturo Vazquez-Almazan \\ Division de Tecnología y Proyectos, \\ MABE, Queretaro, Mexico \\ arturo.vazquez@mabe.com.mx
}

Joaquin Acevedo-Mascarua

Escuela de Ingenieria y Ciencias,

Tecnologico de Monterrey, Monterrey,

Mexico

jacevedo@tec.mx

Eduardo Flores-Villalba*

Escuela de Medicina y Ciencias de la

Salud, Tecnologico de Monterrey, Monterrey, Mexico

eduardofloresvillalba@tec.mx

\section{*Corresponding author.}

Permission to make digital or hard copies of all or part of this work for personal or classroom use is granted without fee provided that copies are not made or distributed for profit or commercial advantage and that copies bear this notice and the full citation on the first page. Copyrights for components of this work owned by others than ACM must be honored. Abstracting with credit is permitted. To copy otherwise, or republish, to post on servers or to redistribute to lists, requires prior specific permission and/or a fee. Request permissions from permissions@acm.org.

ICBET '21, March 17-20, 2021, Tokyo, Japan

\section{ABSTRACT}

Herein we describe the modular design and manufacturing of an emergency ventilator based on cyclical compression of a resuscitation bag to face the COVID-19 pandemic. This was done to mitigate

(C) 2021 Association for Computing Machinery. ACM ISBN 978-1-4503-8789-7/21/03 . \$ \$15.00

https://doi.org/10.1145/3460238.3460255 
the staggering conditions to supply these medical devices under challenging scenarios of need and logistics. The design is based on international standards and commissions for medical electrical equipment, particular requirements for basic safety, electromagnetic compatibility, and essential performance of critical care and emergency ventilators. The modular design is capable of providing four ventilation modes: volume/pressure mandatory ventilation and volume/pressure assisted ventilation. After testing with artificial lungs, calibration, and validation instruments it was found that the main ventilation parameters achieved are: maximum tidal volume of $700 \mathrm{~mL}$, maximum pressure of $50 \mathrm{cmH} 2 \mathrm{O}$, inspiration/expiration ratio up to $1: 4$ at 30 breaths per minute. The MEDIIK designation is derived from the mayan word $i k$ ' which means wind.

\section{CCS CONCEPTS}

- Hardware; • Robustness; - Design for Manufacturability; • Process Variations;

\section{KEYWORDS}

COVID-19, mechanical ventilation, resuscitation bag actuator, biomedical devices

\section{ACM Reference Format:}

Javier Vazquez-Armendariz, Victor Segura Ibarra, Luis H. Olivas-Alanis, Jan Lammel-Lindemann, J. Israel Martinez-Lopez, Erick Ramirez-Cedillo, Hiram Uribe-Hernandez, Ricardo Liñan-Garcia, Rogelio Letechipia-Duran, Marcos D. Moya-Bencomo, Agustin Carvajal-Rivera, Azael Cortes-Capetillo, Nicolas J. Hendrichs-Troeglen, Miguel Mendoza-Machain, Arturo VazquezAlmazan, Cesar Caamal-Torres, Julio Noriega-Velasco, Joaquin AcevedoMascarua, Adriana Vargas-Martinez, Eduardo Gonzalez-Mendivil, Eduardo Flores-Villalba, and Ciro A. Rodriguez. 2021. MEDIIK: Design and Manufacturing of an Emergency Ventilator Against COVID-19 Pandemic. In 2021 11th International Conference on Biomedical Engineering and Technology (ICBET '21), March 17-20, 2021, Tokyo, Japan. ACM, New York, NY, USA, 9 pages. https://doi.org/10.1145/3460238.3460255

\section{INTRODUCTION}

The SARS-CoV-2 outbreak that is currently occurring around the world has caused surprising and unforeseen challenges for healthcare systems around the world. The high transmission rate and long incubation periods of the COVID-19 virus have cost human lives and resources for societies around the world. Health systems have faced a lack of sufficient respiratory support devices, on which many lives depend. Such shortage has even led to the systematic classification of patients in several countries [1]. Although the underlying pathophysiology of the infection has not yet been fully elucidated, the main pathway to the severity of the disease is the exaggerated cytokine cascade that leads to the severe pulmonary inflammatory response [2], [3]. The latter causes inflammation and severe tissue damage, preventing gas exchange [4]. In extreme cases, this leads to the necessity of invasive ventilatory support, often for long periods, ranging from 15 to 20 days on average [5]. Specifically, in the case of Latin America, challenges such as the difficulty of enforcing widespread social distancing and the lack of testing capacity for COVID-19 hampered the chance to prepare against mass transmission [6]. These conditions impose two simultaneous technological challenges for managing the shortage of mechanical ventilators. The first is to develop a design that is scalable to the requirements of the pandemic, thus avoiding the implementation of systemic reasoning and severe triage. Also, there is the need for technical and mechanical robustness to comply with relevant clinical parameters and operate for long time.

Faced with this urgent need, research groups around the world focused their efforts on the development of these devices. Most of them rely on a simple design, based on the compression of a resuscitation bag by mechanical means to control the tidal volume (TV), respiratory rate (RR), expiration/inspiration ratio (I: E). Some of them include the efforts of MIT [7], Rice University [8], UtahStanford [9], OxyGEN [10], and VentilAid [11], to name a few. Ultimately, the United States Food and Drug Administration (FDA) granted an unprecedented emergency deployment permit to these developments for clinical use [12].

There is a wide range of estimates of the number of ventilators needed to care for COVID-19 patients in the United States, ranging from 60,000 to 160,000 [13]. For Mexico, the government estimated the availability of 8,228 ventilators between public and private institutions [14]. It is not clear whether the demand for ventilators during the peak of the pandemic will be met by other means, but there will not be enough ventilators in the coming months for COVID-19 patients if the situation worsens [15]. More than the raw number of devices, their allocation within particular scenarios has proven to be a challenge even for developed countries [16], [17].

As a way to deal with this alarming situation our team worked in the design and manufacture of an emergency ventilator, not intending to replace mechanical ventilators for clinical use, but to comply with most of the operational requirements recommended by the FDA and the Mexican Guide to Ventilatory Management for Emergency Situations. The impetus of the project was possible thanks to the joint effort of the Schools of Engineering and Sciences and the School of Medicine and Health Sciences of Tecnológico de Monterrey, alongside the private industries: MABE, Automation Data Systems, 3D FACTORY MX, and the Covid Task Force Group of the state of Nuevo Leon in Mexico. Next, the most important phases that were carried out for the development of the emergency ventilator will be described. Then, there will be a brief recapitulation of the requirements analyzed for the manufacture of the emergency ventilator. Afterward, a description will be given of the design and manufacturing of the final model. Finally, the results of the validation and evaluation tests of the prototype will be shown.

\section{METHODOLOGY}

\subsection{Analysis of Requirements}

Various guidelines based on international standards for electricalmedical equipment were analyzed to understand the requirements to be met in the design, manufacture, and operation of a mechanical ventilator, such as: a) ISO 80601-2-12: 2020 in part 2-12 stands out: particular requirements for basic safety and essential performance of critical care ventilators, and b) IEC 60601-1 standard for electronic-medical equipment was consulted, in its part 1-2: general requirements for basic safety, essential performance, and electromagnetic compatibility. We also considered the guidelines recommended by governmental agencies such as the FDA (AMII guidelines and Appendix A), the Federal Commission for the Protection against Sanitary Risks (COFEPRIS, Mexico), the Australian 
Table 1: Summary of the general requirements for an emergency ventilator as stated by different guidelines.

\begin{tabular}{|c|c|}
\hline Characteristic & Description \\
\hline Ventilation Mode & $\begin{array}{l}\text { Must have Continuous Mandatory Ventilation (CMV) } \\
\text { - Volume Control (VC-CMV) } \\
\text { - Pressure Control (VP-CMV) } \\
\text { Could have Assisted Control (AC) } \\
\text { - Volume Control (VC-AC) } \\
\text { - - Pressure Control (PC-AC) }\end{array}$ \\
\hline Tidal Volume & Must have a $400 \mathrm{ml}$ setting (Optional $200-800 \mathrm{ml}$ range) \\
\hline Respiratory Rate & $5-30$ breaths per minute $(\mathrm{RR})$ \\
\hline $\begin{array}{l}\text { Positive End-Expiratory Pressure } \\
\text { (PEEP) }\end{array}$ & $5-25 \mathrm{cmH}_{2} \mathrm{O}$ \\
\hline Flow & $<100 \mathrm{~L} / \mathrm{min}$ \\
\hline Pressure & $<50 \mathrm{cmH}_{2} \mathrm{O}$, safe valve open at $50 \mathrm{cmH}_{2} \mathrm{O}$ \\
\hline $\mathrm{I}: \mathrm{E}$ & Must have a 1:2 setting (Optional 1:1 - 1:3 range) \\
\hline Audible and visible alarms & $\begin{array}{l}\text { High priority } \\
\text { - High airway pressure } \\
\text { - Obstruction in the gas pathway } \\
\text { - } 5 \text { minutes battery left alarm } \\
\text { - Low or high respiratory frequency } \\
\text { Medium priority } \\
\text { - Low or high oxygen level } \\
\text { - Low or high expired volume } \\
\text { - High or Low PEEP limit } \\
\text { - } 10 \text { minutes battery left alarm } \\
\text { - Technical failure } \\
\text { - Disconnection } \\
\text { Low priority } \\
\text { - Switch to the internal electrical power source } \\
\text { - Gas supply failure }\end{array}$ \\
\hline Gas supply & $\begin{array}{l}\text { Standard } 22 \mathrm{~mm} \text { outside diameter male connectors for patient breathing system and connection to } \\
\text { standard oxygen connectors }\end{array}$ \\
\hline Power supply and functioning & $\begin{array}{l}\text { - Back up electrical source for powering the ventilator at least } 30 \text { minutes or optional to two } 2 \\
\text { hours } \\
\text { - Adaptable for } 110 \text { or } 240 \text { VAC } \\
\text { - Operating for } 14 \text { days in a } 100 \% \text { duty cycle }\end{array}$ \\
\hline $\begin{array}{l}\text { Infection Control and Biological } \\
\text { safety }\end{array}$ & $\begin{array}{l}\text { - Disposable or designed reusable parts in contact with the patient } \\
\text { - Impermeable and cleanable case (IP21 degree of protection) } \\
\text { - Could have an HMEF-bacterial-viral filter } \\
\text { - Avoid the use of plasticizers, additives, and PVC }\end{array}$ \\
\hline User Interaction & $\begin{array}{l}\text { - Ease to use and modular design to ease of part replacement } \\
\text { - Screen to show control parameters, real-time values, cumulative hours of operation and alarm } \\
\text { setting and inactivation } \\
\text { - Readable values at least at } 1 \text { meter of distance }\end{array}$ \\
\hline
\end{tabular}

Guide for the Use of COVID Ventilators, and the UK Government's Rapid Manufacturing Ventilation Systems Specification [18], [19]. Table 1 summarizes the essential requirements recommended by these agencies.

\subsection{Design and Components of MEDIIK Emergency Ventilator}

The emergency ventilator, named MEDIIK (from the mayan word ik' which means wind), was based 10-gauge stainless steel sheets with dimensions $50.5 \times 54.5 \times 115 \mathrm{~cm}$. A protective ${ }^{1} / 4$-inch clear acrylic shell was fabricated to prevent external disturbances during compression of the resuscitation bag. A support table made of 30-mm aluminum profiles (Rexroth, Lohr am Main, Germany), supported by 4 heavy-duty 100-mm diameter wheels (GBL Castor Wheels, UK) as seen in Figure 1. M3 screws and nord-lock lock washers (Nord-Lock International AB, Malmö, Sweden) were used in the assembly. Figure $1 \mathrm{a}-\mathrm{c}$ shows some of the main components. 
Given the main requirements established by the regulatory agencies, the delivery of a maximum tidal volume of $800 \mathrm{~mL}$ and a maximum inspiratory pressure of $50 \mathrm{cmH} 2 \mathrm{O}$ were defined as a recommendation to reduce the risk of barotrauma. To meet this delivery capacity, a resuscitation bag (adult size, $1600 \mathrm{cc}$ ) is compressed through a motorized pallet, prototyped by additive manufacturing in an M300 Plus printer (Zortrax, Olszytn, Poland) and manufactured by plastic mold injection. To estimate the torque required to compress the resuscitation bag and define the type and model of the required motor, power calculations were performed [7]. The calculation considered the most demanding clinical scenarios, simulating a maximum respiratory rate (FMAX $=30 \mathrm{RR}$ ), maximum inspiratory pressure $(\mathrm{PMAX}=50 \mathrm{cmH} 2 \mathrm{O})$, the maximum I: E ratio $(\mathrm{r}=1: 4)$, and some characteristic measurements of the paddle compression designed. During the calculation operation, safety factors equal to 2 were considered.

After computing the demanding scenarios, the maximum force subjected to the compression paddle was found to be approximately $80[\mathrm{~N}]$, and the torque required by the motor was $12[\mathrm{~N} / \mathrm{m}]$ requiring almost $50[\mathrm{~W}]$ of power. With this information and to satisfy the requested torque demand, a 23HS45-4204S NEMA 23 series stepper motor (Shenzhen, China), and a KL-23GH101S 10: 1 gearbox (Shenzhen, China) were used. For motor control, a stepper controller model 2DM860F (Just Motion Control, Shenzhen, China) and an S-600-60 power supply (GYU \& PW, Shenzhen, China) were used. The compression paddle was designed with a surface that provides smooth contact with the resuscitation bag.

The general control was centralized in an Arduino DUE®microcontroller (Piedmont, Italy). The regulation of the VT, the respiratory rate, and the I / E ratio is individually adjusted employing three precision potentiometers. A rotary selector was incorporated for the selection of ventilation modes and configuration of operating parameters, buzzer for audible alarm notification, and an LED for visual alarms were included. A $20 \times 4$ segment LCD screen with I2C communication module (Steren ${ }^{\circledR}$, Monterrey, N.L., Mexico) and an Arduino UI ${ }^{\circledR}$ microcontroller (Piedmont, Italy) were used to display the variables. A 7 "touch screen controlled by a Raspberry Pi 3®Model B (Raspberry Pi Foundation, Cambridge, UK) was also added to display the most important ventilation curves and parameters. A backup battery with a minimum durability of 3 hours was integrated.

To improve feedback, performance, control, and execution of the ventilation modes, two Zephyr flow sensors model HAFUHT0200L4AXT (Honeywell, Charlotte, NC, United States) were integrated. The first flow sensor was incorporated into the inhalation line connected to the air outlet of the resuscitation bag to measure the volume of air delivered to the patient. The second flow sensor was connected to the outlet of the exhalation line to measure the effective volume. Also, a 2SMPP-03 pressure sensor (Omron Electronics, Kyoto, Japan) was placed inside the housing and connected to the inhalation line for monitoring and prevention of barotrauma. A Figaro KE-25 oxygen sensor (Maxell, Osaka, Japan) and a De-Wit 2WSS solenoid valve (De-Wit, VA, United States) were used for $\mathrm{O} 2$ level measurement and for pressure containment within of the respiratory circuit and cycle control, respectively. A 2700 RPM fan (Steren ${ }^{\circledR}$, Monterrey, N.L., Mexico) was also installed to cool the electronic components inside the structure and an ON
/ OFF actuator to turn on the system (Steren ${ }^{\circledR}$, Monterrey, N.L. Mexico).

For both the power supply of the micro-step controller, the NEMA 23 motor, and the electronic components, three voltage sources models S-600-60, MS-36-12 and S-50-5 (GYU \& PW, Shenzhen, China), respectively. A capacitive NPN sensor LJC18A3-HZ / BX (Tainan, Taiwan) was added to detect the presence of the paddle at the end of the stroke, thus ensuring a repeatable pathway in each compression. Figure 2 shows a diagram of the electronic components used in the MEDIIK emergency ventilator. The yellow box details the sensory instrumentation used, with which it was possible to achieve closed-loop control and the execution of different ventilation modes (CV-CMV, PC-CMV, VC-AC, and PC-AC). The red box, labeled Power and Power, contains the voltage sources used to power the microcontrollers, the NEMA 23 motor, sensors, and general electronics. Finally, the green block contains the components that will be in contact with the health care provider during the programming of the ventilation modes. The yellow lines shown in the figure represent the direction of the control signals and the red ones to ilustrate the power supply.

\subsection{Subsystems of MEDIIK Emergency Ventilator}

Figure 3 shows a graphical arrangement in the form of a block diagram of the subsystems that make up the MEDIIK emergency ventilator. The yellow lines indicate the direction of the digital input and output signals that correspond to each electronic element. The red lines indicate the power supply of each element, being: 5, 12, 60 VDC, or 120 VAC. Finally, the blue lines indicate the direction of the airflow and the dotted boxes correspond to the elements provided by the hospital's gas infrastructure. The summation points in yellow and red are shown simply to indicate the origin or destination of each signal.

The green area in Figure 3 corresponds to the subsystem called user interface, which corresponds to the elements that will be used or will be in direct contact with the medical equipment, including the ON / OFF switch, interface for setting ventilation parameters, and control modes. The value of each parameter is sent to the Arduino UI®for processing and then to the LCD screens for display. The real-time ventilation curves are processed by the Raspberry $\mathrm{Pi}{ }^{\circledR}$ and then sent to the 7 "touch screen to be viewed by the medical staff.

The blue zone represents the arrangement of the elements found in the prototype's respiratory circuit. A conventional 2-way adult breathing circuit (female connection $22 \mathrm{~mm}, 1.8$ meters) was used. The inspiratory line begins with the oxygen supply found in hospitals. The fraction of inspired oxygen that is delivered to the patient (FiO2) can be controlled manually by the rotameter mounted on the hospital gas supply line, which fills the resuscitation bag with oxygen. The $\mathrm{O} 2$ sensor was included in the ventilator in order for medical staff to measure and adjust oxygen precisely. Subsequently, the resuscitation bag was connected to the flow sensor to measure the volume of air delivered to the patient. This oxygen mix volume supplied in each cycle is controlled by the angle at which the motorized paddle compresses the bag. Similarly, the respiratory rate and the I: E ratio are controlled by the speed with which the 
$\mathbf{a}$

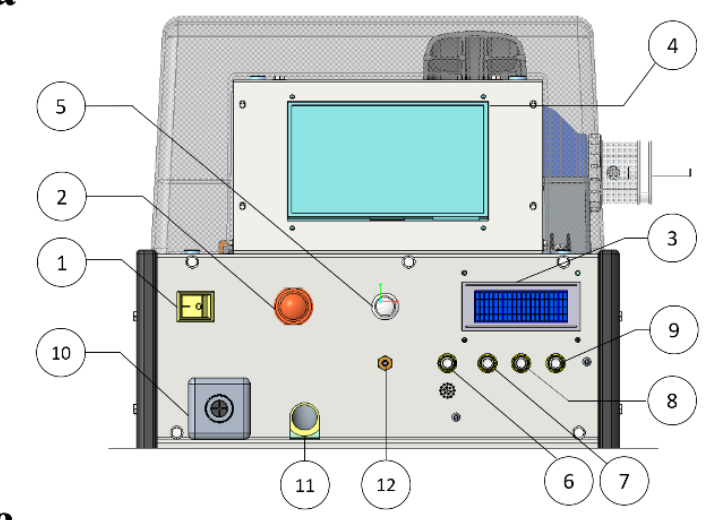

b

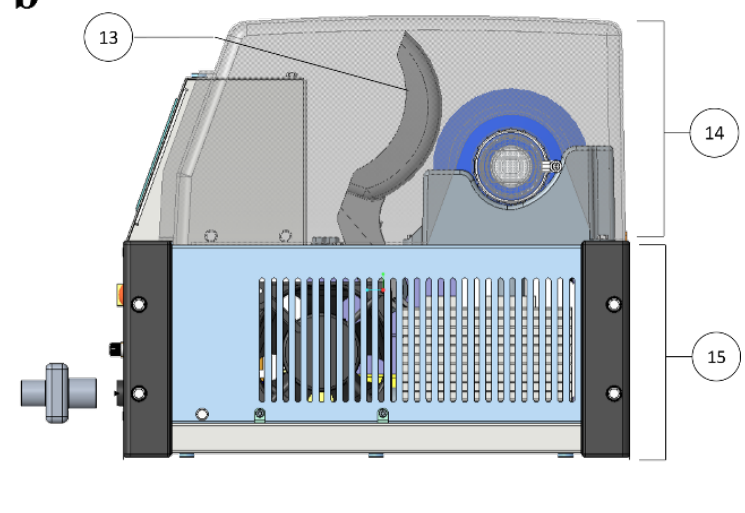

C
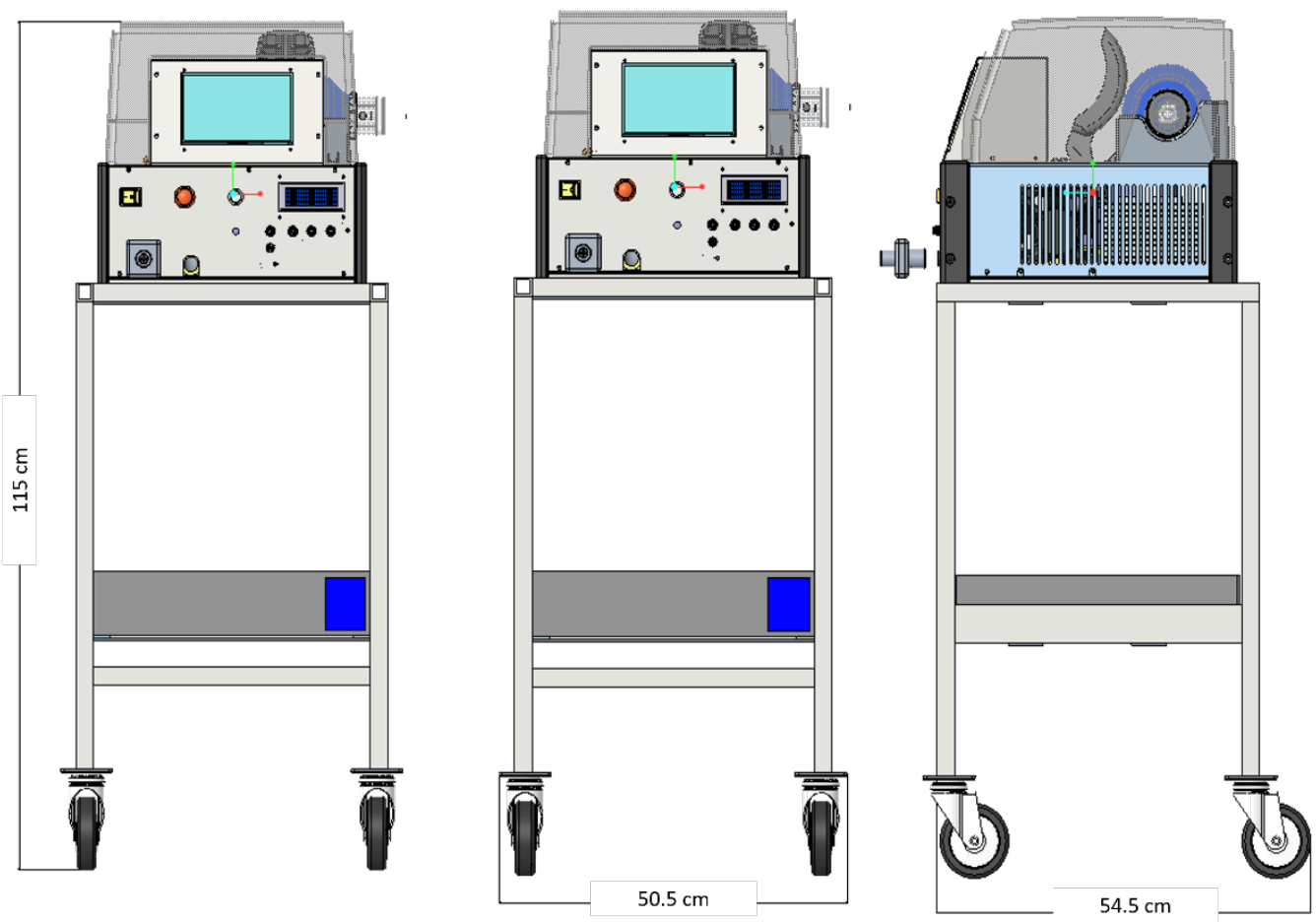

Figure 1: Design of the MEDIIK emergency ventilator. It is capable of offering four ventilation modes: CV-CMV, PC-CMV, VC-AC and PC-AC, TV <700 ml, 0 - 30 RR, I:E - 1:4. Contains audible and visible alarms, measurement of CO2 and O2, flow, volume, and pressure monitoring. a. In the front view: 1 - ON / OFF Button, 2 - LED alarm, 3 - LCD screen, 4 - screen to display ventilation curves, 5 - emergency stop, 6 - button for navigation menu, 7 - TV control button, 8 - RR control button, 9 - I: E control button, 10 - Expiratory port, 11 - Inspiratory port, 12 - Pressure sensing pivot. b. In the side view: 13 - Compression paddle, 14 - Acrylic protective housing, 15 - Electronic component housing. c. MEDIIK overall dimensions.

paddle executes its movement. Both inspiratory and expiratory respiration lines connect to a typical Y connector, with an outlet for the pressure hose. The filter is positioned between the $\mathrm{Y}$ and the endotracheal tube. This leads all air (inhaled and exhaled) to pass through a 0.2-micron HEPA 14 filter. As it passes through the filter, the cleaned exhaled air reaches a solenoid valve that is kept closed during the inspiratory phase, which ensures that all the supplied air does not leave the expiratory part and enter the patient. As a safety mechanism in the event of pressure peaks, the solenoid valve receives an activation signal to open if necessary. The solenoid valve outlet connects to the exhalation flow sensor for effective flow measurement. In the yellow area of Figure 3 are the elements intended for the general control of the prototype. Finally, the red area for the power supplies shows the arrangement of the 5, 12, and 60 VDC voltage sources, which in turn are powered by the 120 VAC connection from the hospital mains. 


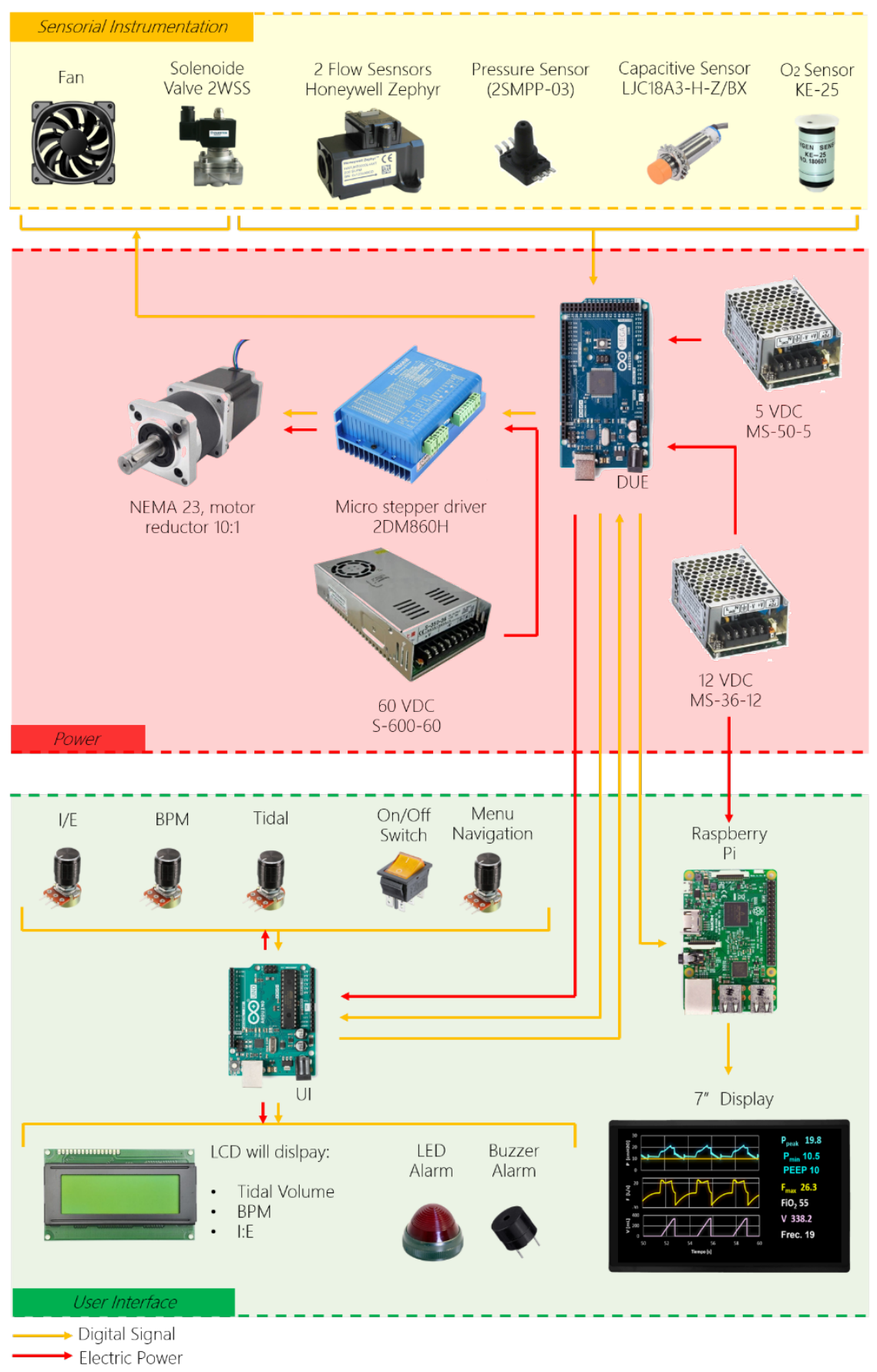

Figure 2: Electronic components used in the MEDIIK emergency ventilator. The yellow block contains the sensory instrumentation used and the red block the power and supply sources. The green block details the components that will interact with the user. The yellow and red lines represent the direction of the control or electrical signal, respectively.

\section{RESULTS}

Table 2 shows the operational confidence ranges guaranteed by the MEDIIK emergency ventilator, and Figure 4 shows the final prototype built. These ranges were obtained based on the latest tests carried out at the National Metrology Center (CENAM, Querétaro, Mexico) and in the Salvador Zubirán National Institute of Medical Sciences and Nutrition (INCMNSZ, Mexico City). To date, work continues to obtain the necessary certifications for the serial 

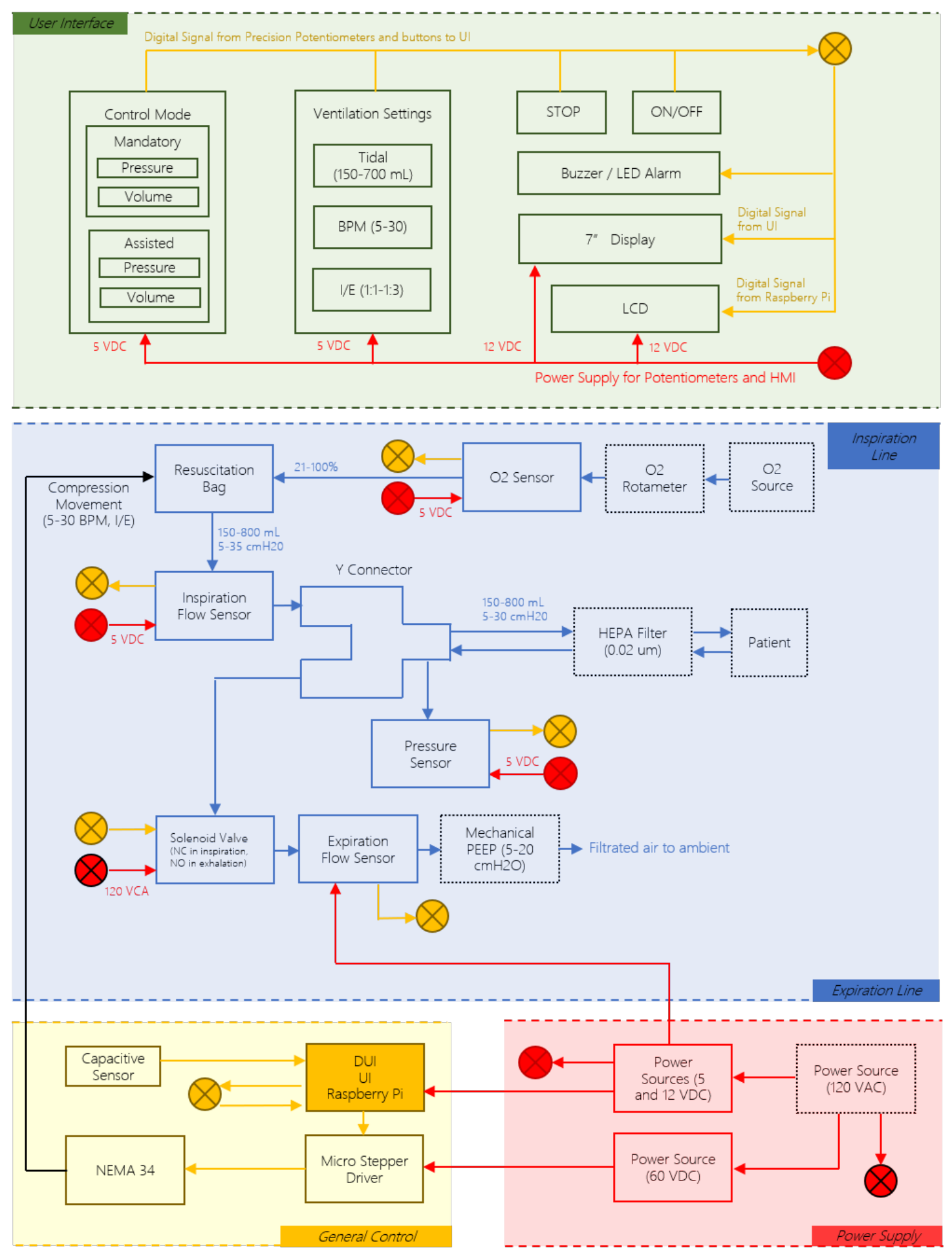

Digital Signal (ES - Entry Signal, ODS - Output Signal)

Electrical Power

Flow of gas

Provi......... Prow by Hospital

Figure 3: MEDIIK subsystems. The green area corresponds to the user subsystem, which will be in direct contact with the medical team. The blue zone corresponds to the ventilatory circuit. The yellow area represents the organization of the control structure and the red area is used to delineate the power supplies. 
Table 2: MEDIIK operational confidence parameters at different pulmonary compliance, resistance and respiratory rates.

\begin{tabular}{|c|c|c|c|c|c|c|c|}
\hline \multirow[t]{3}{*}{ Resistance } & \multirow{3}{*}{$\begin{array}{c}\text { Compliance } \\
\text { RR } \\
\text { PEEP }\left[\mathrm{cmH}_{2} \mathrm{O}\right]\end{array}$} & \multicolumn{2}{|c|}{ Low0.02 [L/cmH $\left.{ }_{2} \mathrm{O}\right]$} & \multicolumn{2}{|c|}{ Medium0.05 $\left[\mathrm{L} / \mathrm{cmH}_{2} \mathrm{O}\right]$} & \multicolumn{2}{|c|}{ High0.1 $\left[\mathrm{L} / \mathrm{cmH}_{2} \mathrm{O}\right]$} \\
\hline & & $10-20$ & $25-30$ & $10-20$ & $25-30$ & $10-20$ & $25-30$ \\
\hline & & \multicolumn{6}{|c|}{$\mathrm{TV}[\mathrm{mL}]$} \\
\hline \multirow[t]{4}{*}{ Low $5\left[\mathrm{cmH}_{2} \mathrm{O} /(\mathrm{L} / \mathrm{s})\right]$} & 5 & $300-450$ & $300-400$ & $300-550$ & $300-450$ & $300-700$ & $300-450$ \\
\hline & 10 & $300-450$ & $300-350$ & $300-500$ & $300-400$ & $300-450$ & $300-400$ \\
\hline & 15 & $300-400$ & $300-350$ & $300-450$ & $300-450$ & - & - \\
\hline & 20 & $300-350$ & 300 & $300-450$ & $300-450$ & - & - \\
\hline Medium & 5 & $300-450$ & $300-350$ & $300-500$ & $300-400$ & $300-550$ & $300-450$ \\
\hline \multirow[t]{3}{*}{$20\left[\mathrm{cmH}_{2} \mathrm{O} /(\mathrm{L} / \mathrm{s})\right]$} & 10 & $300-450$ & $300-350$ & $300-500$ & $300-350$ & $300-450$ & $300-400$ \\
\hline & 15 & $300-400$ & $300-350$ & $300-450$ & $300-350$ & - & - \\
\hline & 20 & $300-350$ & 300 & $300-400$ & 300 & - & - \\
\hline \multirow[t]{2}{*}{ High $50\left[\mathrm{cmH}_{2} \mathrm{O} /(\mathrm{L} / \mathrm{s})\right]$} & 5 & $300-400$ & 300 & $300-400$ & $300-400$ & $300-450$ & 300 \\
\hline & 10 & $300-450$ & - & 300 & - & $300-350$ & - \\
\hline
\end{tabular}
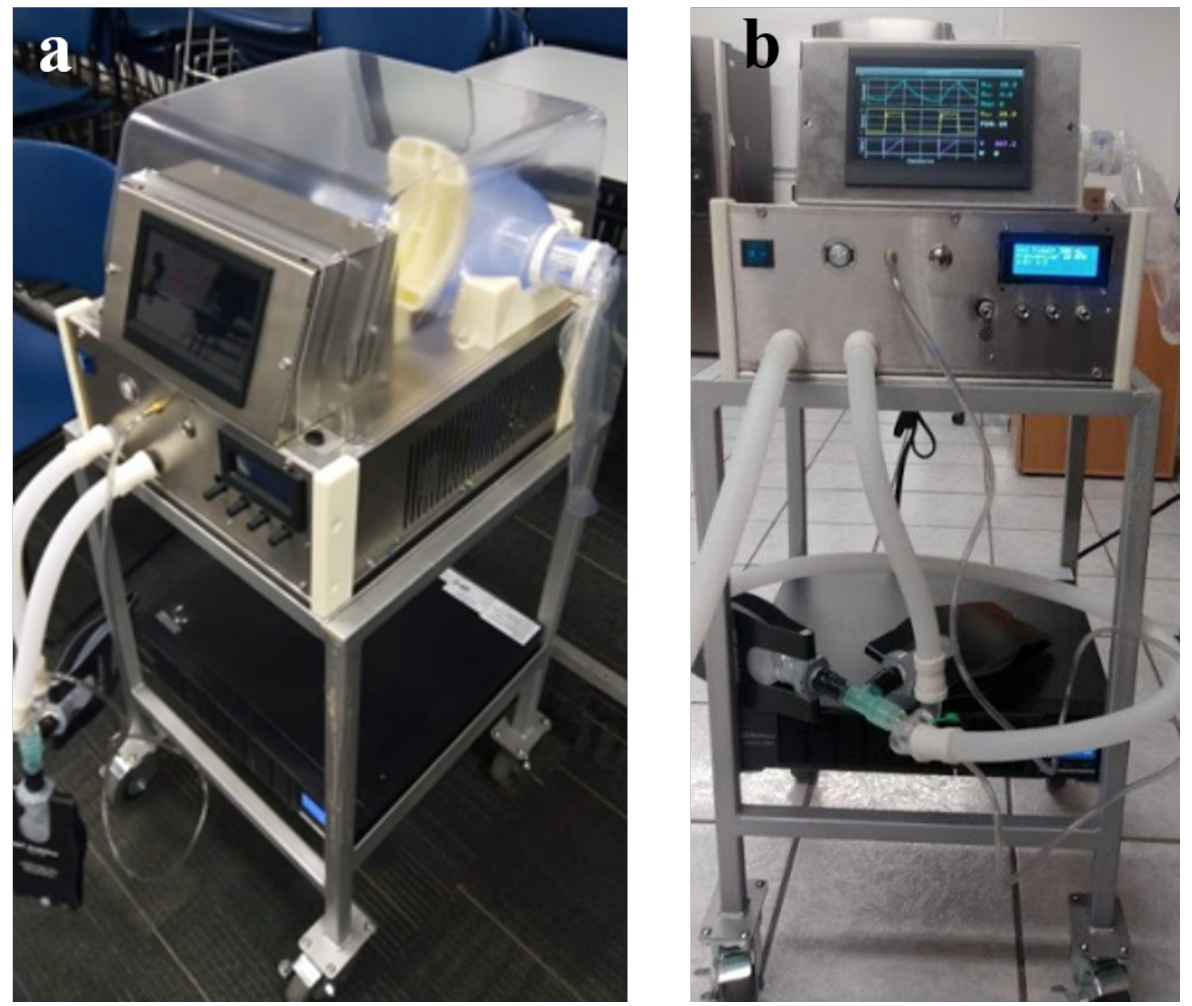

Figure 4: MEDIIK emergency ventilator. a. Lateral view. b. Front view of MEDIIK emergency ventilator. It is capable of supplying ventilation in 4 modes: CV-CMV, PC-CMV, VC-AC, and PC-AC.

production of the prototype. However, obtaining these confidence ranges is one of the most important achievements of the project in general. With these results, the reliability of the device can be guaranteed before the regulatory entities.

\section{CONCLUSIONS}

The high rate of transmission of the COVID-19 pandemic and the fragile technological platforms in hospitals have forced doctors to decide whether or not a seriously ill patient should receive ventilatory therapy. They have even found it necessary to ration the use of ventilators among young people and adults, depending on their chances of recovery and survival. This is a difficult decision that clinicians have to face to get the most out of the few ventilators available. 
As an effort to mitigate these conditions, a collaboration was carried out between academy and industry. The result of this effort was the design and manufacture of the MEDIIK emergency ventilator, which is capable of offering up to 4 ventilation modes (CV-CMV, PC-CMV, VC-AC, and PC-AC). Testing has been extensive, showing good performance within design requirements. Work is still ongoing to obtain the necessary certifications for its mass production and clinical use.

\section{REFERENCES}

[1] Alper Yilmaz, Omar Javed, and Mubarak Shah. 2006. Object tracking: A survey. ACM Comput. Surv. 38, 4 (December 2006), 13-es. https://doi.org/10.1145/1177352. 1177355 [1] R. D. Truog, C. Mitchell, and G. Q. Daley, "The Toughest Triage Allocating Ventilators in a Pandemic," N Engl J Med, p. NEJMp2005689, Mar. 2020, doi: 10.1056/NEJMp2005689.

[2] M. Z. Tay, C. M. Poh, L. Rénia, P. A. MacAry, and L. F. P. Ng, "The trinity of COVID-19: immunity, inflammation and intervention," Nat Rev Immunol, pp 1-12, Apr. 2020, doi: 10.1038/s41577-020-0311-8.

[3] M. Cascella, M. Rajnik, A. Cuomo, S. C. Dulebohn, and R. Di Napoli, "Features, Evaluation and Treatment Coronavirus (COVID-19)," in StatPearls, Treasure Island (FL): StatPearls Publishing, 2020.

[4] K. Iyengar, S. Bahl, Raju Vaishya, and A. Vaish, "Challenges and solutions in meeting up the urgent requirement of ventilators for COVID-19 patients," Diabetes \& Metabolic Syndrome: Clinical Research \& Reviews, vol. 14, no. 4, pp. 499-501, Jul. 2020, doi: 10.1016/j.dsx.2020.04.048.

[5] L. Rosenbaum, "Facing Covid-19 in Italy - Ethics, Logistics, and Therapeutics on the Epidemic's Front Line," N Engl J Med, vol. 382, no. 20, pp. 1873-1875, May 2020, doi: 10.1056/NEJMp2005492.

[6] R. P. Alvarez, P. R. Harris, R. P. Alvarez, and P. R. Harris, "COVID-19 en América Latina: Retos y oportunidades," Revista chilena de pediatría, vol. 91, no. 2, pp 179-182, Apr. 2020, doi: 10.32641/rchped.vi91i2.2157.

[7] "MIT E-VENT | Emergency ventilator design toolbox." https://e-vent.mit.edu/ (accessed May 01, 2020).

[8] "Student invention gives patients the breath of life." https://news.rice.edu/2019/ 05/01/student-invention-gives-patients-the-breath- of-life-2/ (accessed May 01,
2020).

[9] H. Li et al., "Utah-Stanford Ventilator (Vent4US): Developing a rapidly scalable ventilator for COVID-19 patients with ARDS," Emergency Medicine, preprint, Apr. 2020. doi: 10.1101/2020.04.18.20070367.

[10] Secretaria General Iberoamericana, "OxyGEN Project." https://www.oxygen. protofy.xyz/?lang=es (accessed May 01, 2020).

[11] “Open-Source solutions," VentilAid. https://www.ventilaid.org/ (accessed May 01, 2020).

[12] C. for D. and R. Health, "Ventilators and Ventilator Accessories EUAs," FDA, Mar. 2020, Accessed: Dec. 12, 2020. [Online]. Available: https://www.fda.gov/medicaldevices/coronavirus-disease-2019-covid-19-emergency-use-authorizationsmedical-devices/ventilators-and-ventilator-accessories-euas.

[13] D. Newsome, "The Worst-Case Estimate for U.S. Coronavirus Deaths - The New York Times," The New York Times, p. 9.

[14] "\#ConferenciaDePrensa: \#Coronavirus \#COVID19 | 20 de marzo de 2020 YouTube." https://www.youtube.com/watch?v=f79tm7-c-_Q\&t=501s (accessed May 01, 2020).

[15] M. L. Ranney, V. Griffeth, and A. K. Jha, "Critical Supply Shortages - The Need for Ventilators and Personal Protective Equipment during the Covid-19 Pandemic," New England Journal of Medicine, vol. 382, no. 18, p. e41, Apr. 2020, doi: 10.1056/NEJMp2006141.

[16] D. Adelman, "Thousands Of Lives Could Be Saved In The US During The COVID-19 Pandemic If States Exchanged Ventilators," Health Affairs, p. 10.1377/hlthaff.2020.00505, Apr. 2020, doi: 10.1377/hlthaff.2020.00505.

[17] S. Mehrotra, H. Rahimian, M. Barah, F. Luo, and K. Schantz, "A model of supplychain decisions for resource sharing with an application to ventilator allocation to combat COVID-19," Naval Research Logistics, p. nav.21905, May 2020, doi: 10.1002/nav.21905.

[18] C. F. para la P. contra R. Sanitarios, "Disposiciones para la adquisición y fabricación de ventiladores, durante la emergencia de salud pública por coronavirus 2019 (COVID-19)," gob.mx. http://www.gob.mx/cofepris/articulos/disposicionespara-la-adquisicion-y-fabricacion-de-ventiladores-durante-la-emergenciade-salud-publica-por-coronavirus-2019-covid-19?idiom=es (accessed May 01, 2020).

[19] "Specification for Rapidly Manufactured Ventilator System (RMVS)," GOV.UK. https://www.gov.uk/government/publications/specification-for-ventilators-tobe-used-in-uk-hospitals-during-the-coronavirus-covid-19-outbreak/rapidlymanufactured-ventilator-system-rmvs (accessed May 01, 2020). 